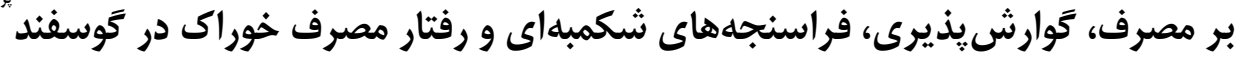

\author{
محسن دهقانى'، محمد مهدى شريفى حسينى '، اميد ديانى 'ّ على مداحيانع

\begin{tabular}{|c|}
\hline 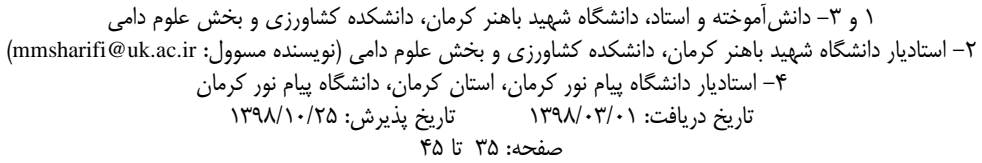 \\
\hline
\end{tabular}

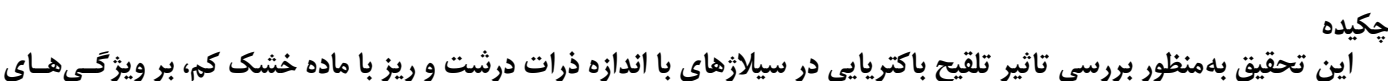

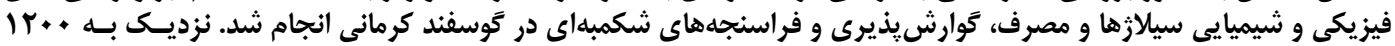

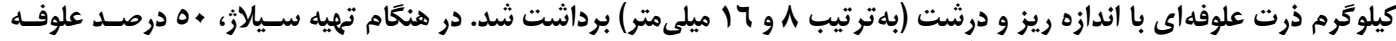

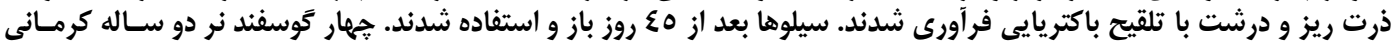

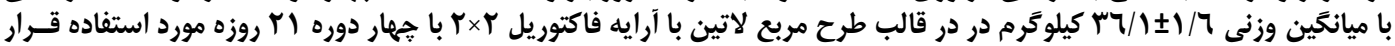

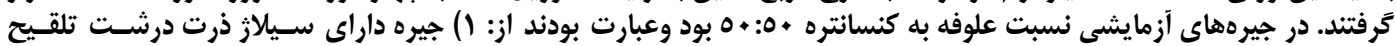

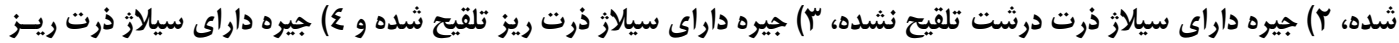

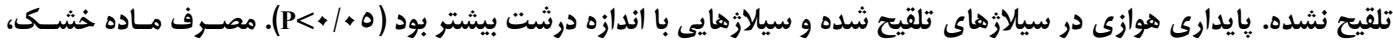

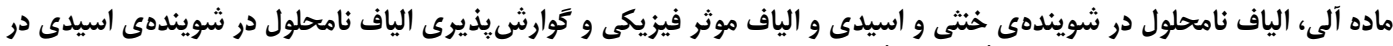

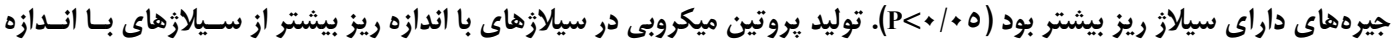

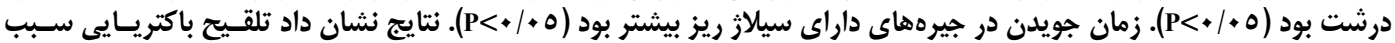

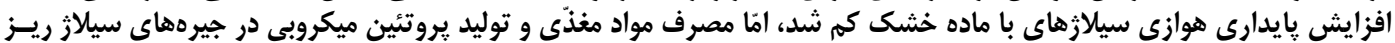

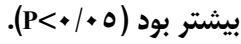

وازههاى كليدى: بايدارى هوازى، سيلاز ذرت، الياف موثر فيزيكى، فراسنجهاى شكمبهاى، يروتئين ميكروبى

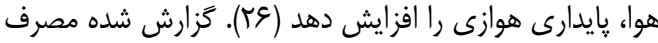

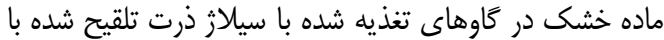

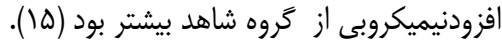

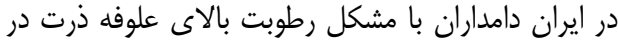

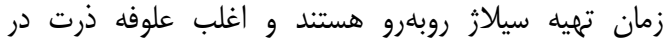

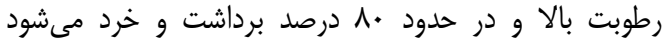

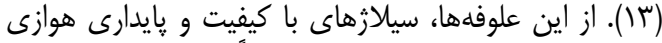

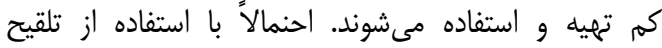

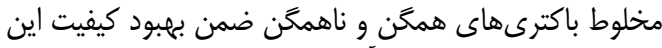

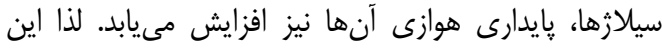

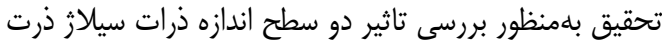

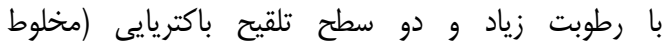

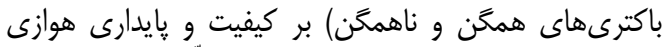

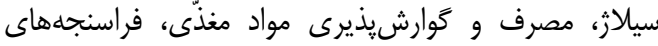
شكمبادى و رفتار مصرف خوراك در كوسفند كرمانى انجام

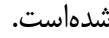

\section{مواد و روشها مهام}

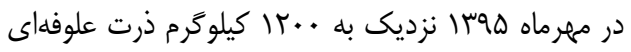

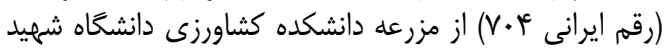

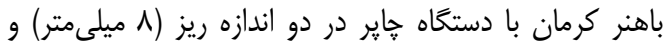

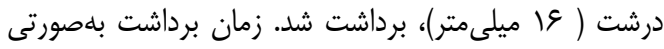

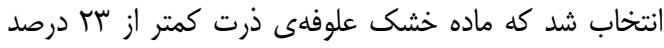
بود. در زمان تهيه سيلاز، محلول تلقيح باكتر يائيى بايواستامبيل

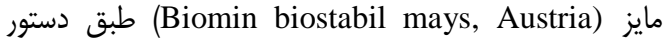
كارخانه توليد كننده، به •ه درصد علوفه ذرت ريز و درشت
در ايران علوفه اصلى در تغذيه نشخواركنندكان سيلاز

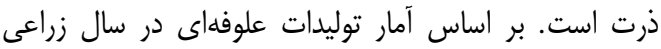

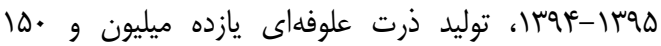

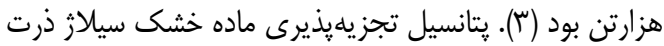

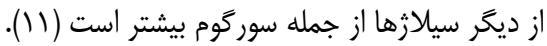

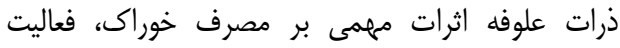
جويدن، فرايند هضم شكمبهاى و و عملكرد در كاروهاى شئى شيرى

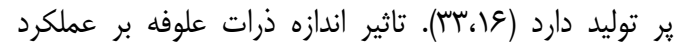

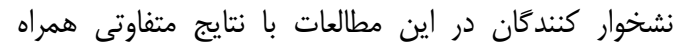

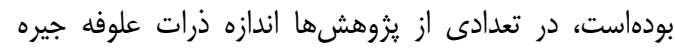

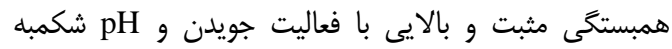
داشت (كَr)، اما در تعدادى از مطالعات، اين همبستكى ها وجود

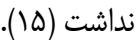

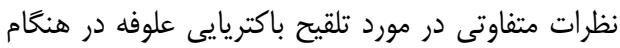

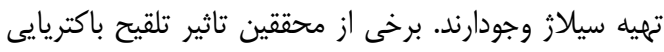

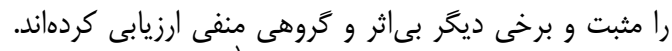

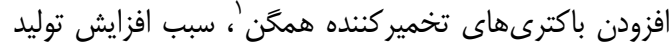

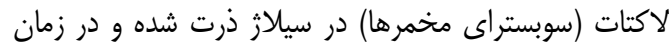

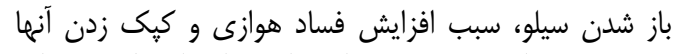

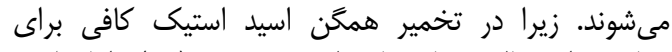

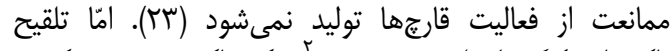

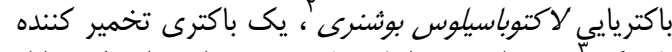

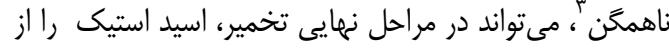

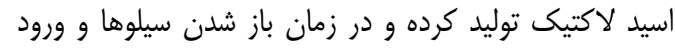




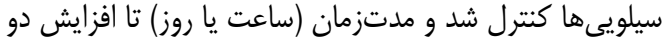

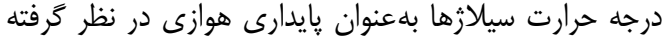

شد (r).

براى اجراى آزمايش از جهار راس گُوسفند نر دو ساله نزاد

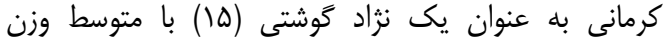

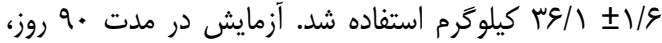

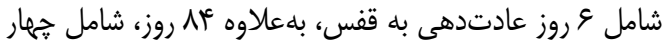

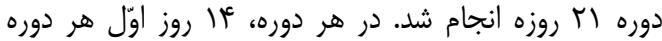

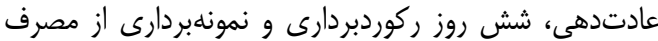

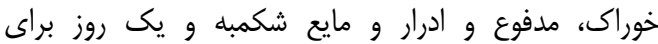

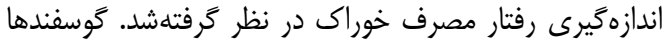

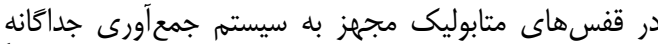

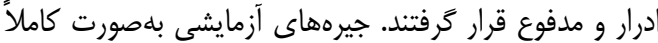

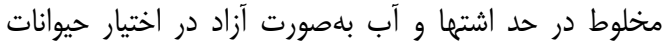

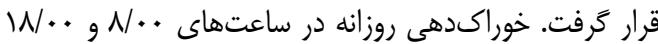

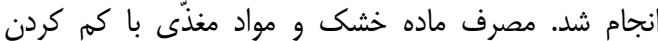

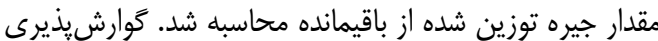

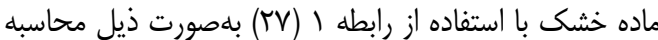

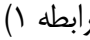

$\mathrm{DMD}=\mathrm{DM}$ Intake-Faecal DM excreted/DM Intake

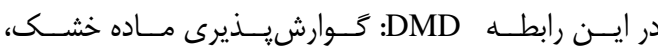

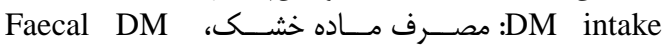

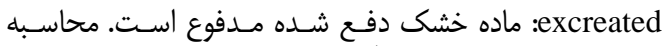

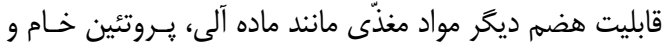

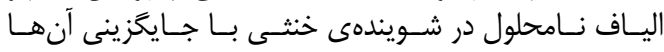

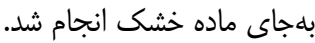

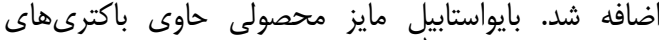

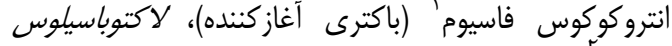

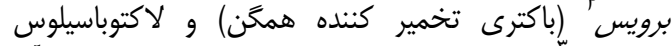

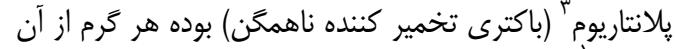

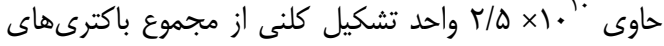

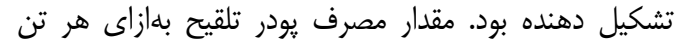

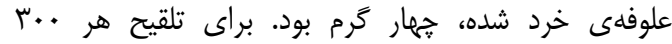

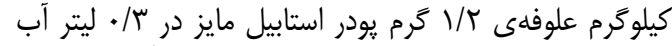

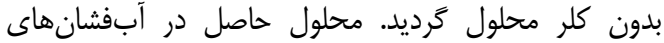

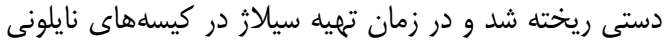

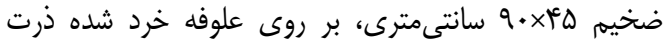

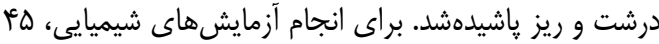

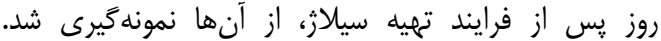

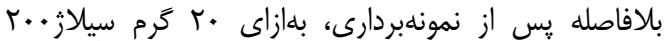

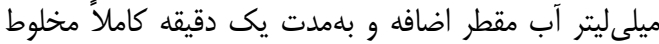

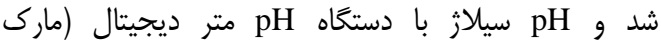
مدل س.• Elmetron

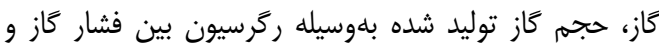

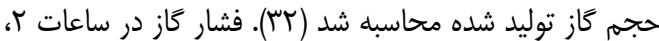

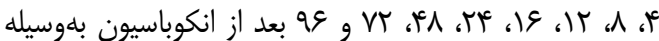

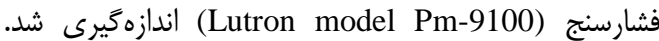
براى تخمين مولفههاى كنيتيك توليد كاز (a و a) از نرمافزار Fitcurve

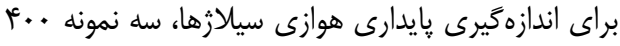

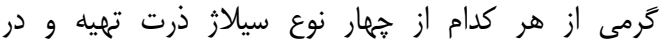

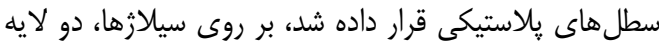

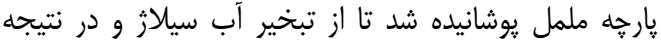

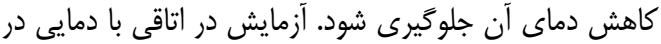

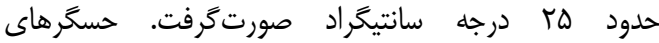

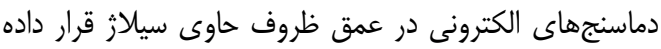

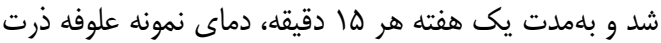


جدول1 - اجزاء (درصد) و تركيب شيميايى جيرههاي آزمايشى (درصد ماده خشك) Table 1. ingrident (\%) and chemical composition of experimental diets (DM basis)

\begin{tabular}{|c|c|c|c|c|}
\hline \multicolumn{2}{|c|}{ ريز } & \multicolumn{2}{|c|}{ درشت } & اندازه ذرات سيلاز ذرت \\
\hline- & $\dashv$ & - & $\dashv$ & اجزاء جيرهها \\
\hline $50 / C$ & $50 / C$ & $5 \mathrm{C} / \mathrm{C}$ & $5 \mathrm{C} / \mathrm{C}$ & سيلاز ذرت \\
\hline $2=/ C$ & $2 E / C$ & $2 E / C$ & $2=/ C$ & دانه جو \\
\hline $7 / 5 C$ & $6 / 5$ & $\varepsilon / C$ & $\mathrm{IC} / \mathrm{C}$ & دانه ذرت \\
\hline $1 \mathrm{C} / \mathrm{C}$ & $1 \mathrm{C} / \mathrm{C}$ & $11 / \mathrm{C}$ & $\mathrm{IC} / \mathrm{C}$ & كنجاله سويا \\
\hline $7 / 5$ & $\varepsilon / 5$ & $\epsilon / C$ & $5 / C$ & سبوس گَندم \\
\hline $1 / C$ & $1 / C$ & $1 / C$ & $1 / \mathrm{C}$ & مكمل مواد معدنى و ويتامينىــ \\
\hline$C / 5$ & $C / 5$ & $\mathrm{C} / 5$ & $C / 5$ & سنى آهك . \\
\hline$C / 5$ & $C / 5$ & C/5 & C/5 & نمك \\
\hline & & & & تركيب شيميايى و انرزى قابل سوخت و ساز \\
\hline $5 \mathrm{C} / \mathrm{E}$ & $58 / 4$ & $5 \mathrm{E} / \mathrm{S}$ & $58 / 5$ & ماده خشك (درصد) \\
\hline $9 / C$ & 9C/5 & $9 / / 6$ & $9 \mathrm{C} / \mathrm{\varepsilon}$ & ماده آلى (درصد) \\
\hline $1 \equiv / 2$ & $1 \equiv / \equiv$ & Iミミ & $1 \equiv / 2$ & يروتئين خام (درصد) \\
\hline$\Xi / C$ & $4 / C$ & 汇 & $4 / C$ & عصاره اترى (درصد) \\
\hline $35 / 6$ & $3 E / 5$ & $3 z / 6$ & $38 / 7$ & الياف نامحلول در شويندهى خنثى (درصد) \\
\hline 1/4/4 & $1 \mathrm{C} / 2$ & $2 / 5$ & $2 / 5$ & الياف نامحلول در شويندهى اسيدى (درصد) \\
\hline$E / E$ & $6 / 4$ & $6 / 4$ & $6 / \Xi$ & كلسيم (گرم) \\
\hline $4 \sqrt{2}$ & $4 / 2$ & $4 / C$ & 汇 & فسفر(كرم) \\
\hline $2 / 4$ & $2 / 4$ & $2 / \Xi$ & $2 / \Xi$ & انرزى قابل سوخت وساز (محاكالرى) \\
\hline
\end{tabular}

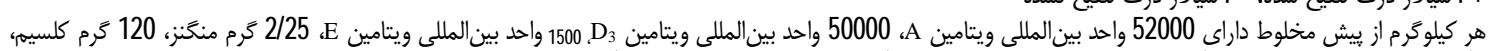

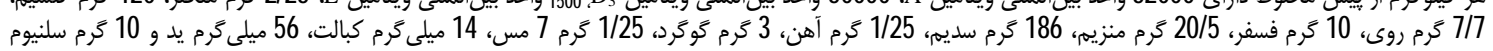

براى تعيين توزيع اندازه ذرات جيرهها و محاسبه عامل و الياف رون

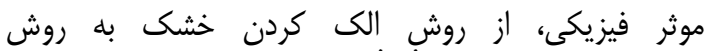

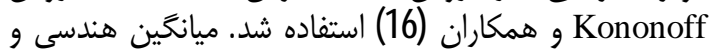

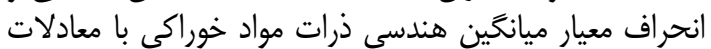

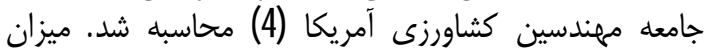

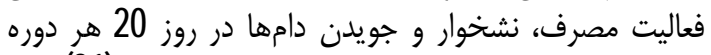

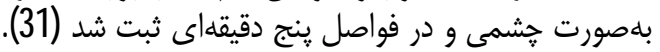

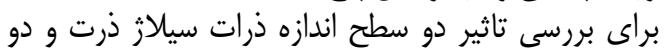

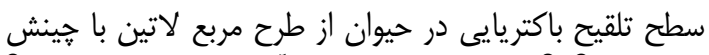

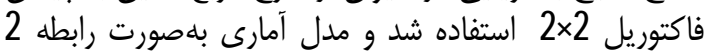

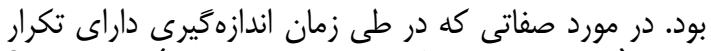
بودند (pH) و نيتروثن آمونياكى مايع شكمبه) از رابطه دارئ 3

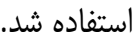
رابطه 2) $\mathrm{y}_{\mathrm{ijkl}}=\mu+\alpha_{\mathrm{i}}+\beta_{\mathrm{j}}+(\alpha \times \beta)_{\mathrm{ij}}+\gamma_{\mathrm{k}}+\delta_{\mathrm{L}}+\mathrm{e}_{\mathrm{ijkL}}$

) رابطه3)

$\mathrm{Y}_{\mathrm{ijklm}}=\mu+\alpha_{\mathrm{i}}+\beta_{\mathrm{j}}+(\alpha \beta)_{\mathrm{ijj}}+\gamma_{\mathrm{k}}+\delta_{\mathrm{L}}+\sigma_{\mathrm{m}}+\mathrm{e}_{\mathrm{ijkLm}}$ در اين مدلها،

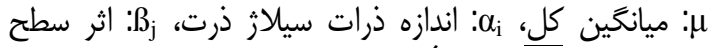

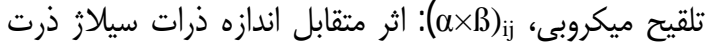

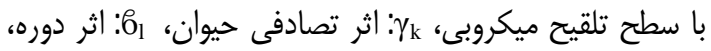

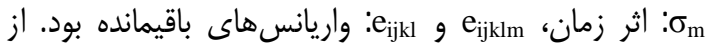

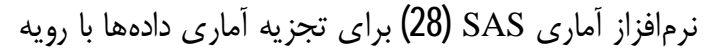

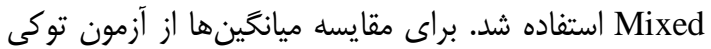
در سطح5 درصد استفاده شد.

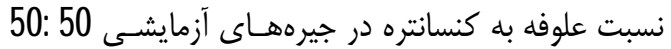

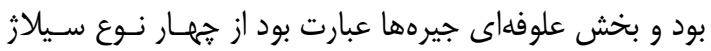
ذرت شامل: سيلازذرت درشت تلقيح تلقيح شده، سيلاز ذرت درت درشت

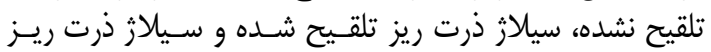
تلقيح نشده (جدول 1).

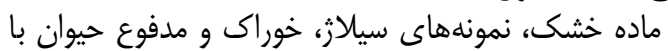

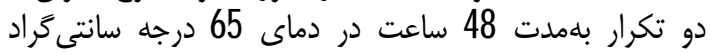

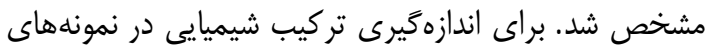

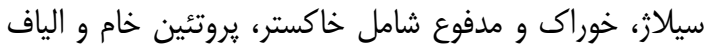

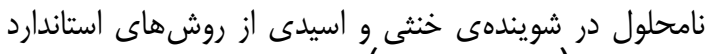

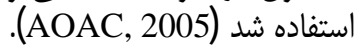

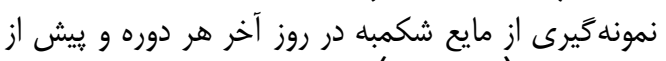

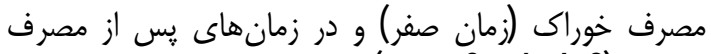

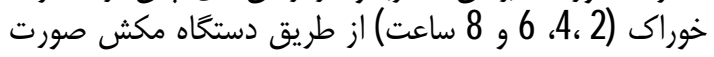

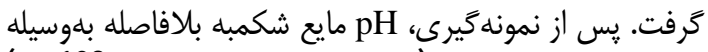

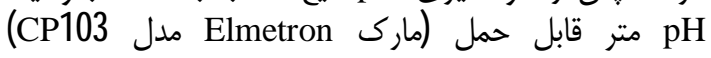

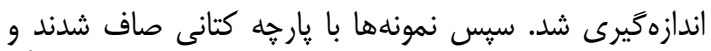

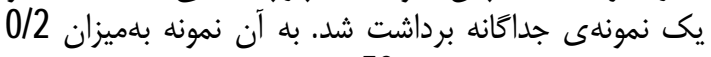

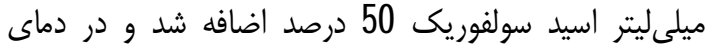

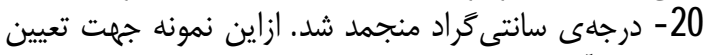

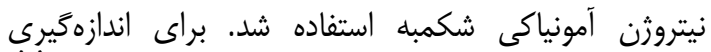

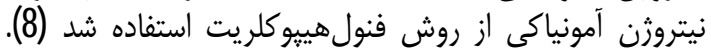

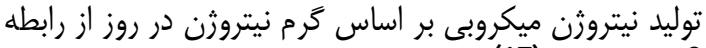

2 استفاده شد (17).

يروتئين ميكروبى $=\frac{x\left(\frac{\mathrm{mmol}}{\mathrm{dgy}}\right) \times 70}{0.116 \times 0.83 \times 1000}$

ميزان جذب يورينها (ميلىمول در روز) X 
باكترى هاى توليدكننده اسيد لاكتيك قرار مى خيــرد (25). امّا سطح تلقيح بر pH تاثير كذار نبار نبود.

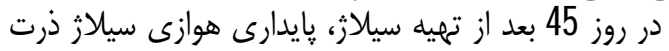

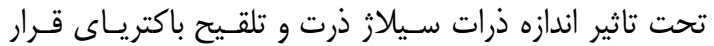

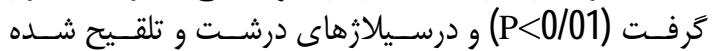
بيشترين بود (P<QOC)

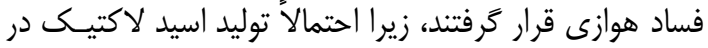

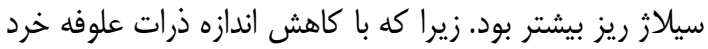

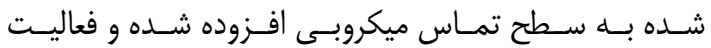

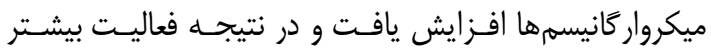

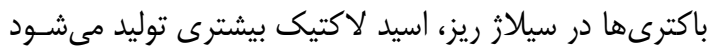

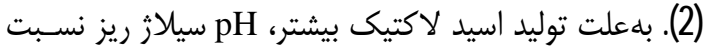

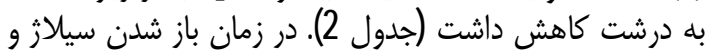

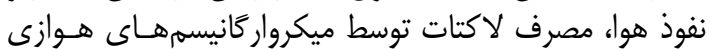

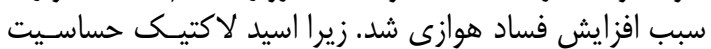

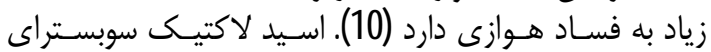

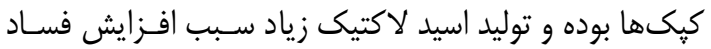

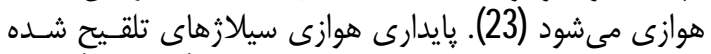

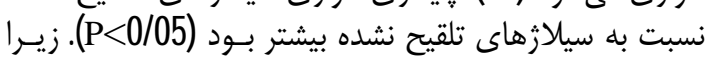

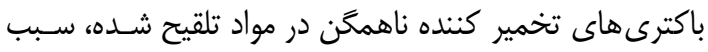

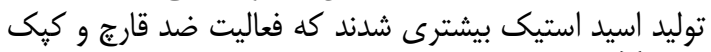

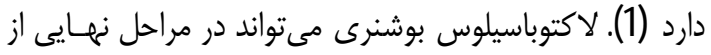

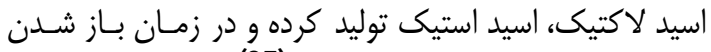
سيلو بايدارى هوازى افزايش مى ايتيد توليد (25).

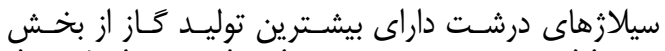

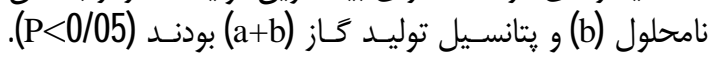

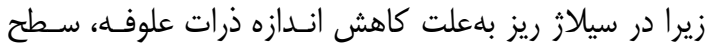

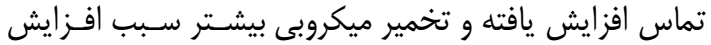

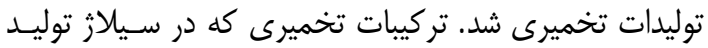

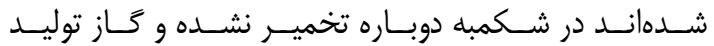

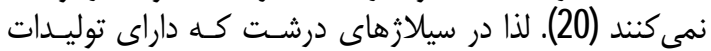

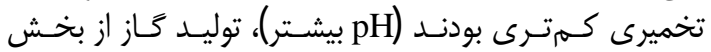

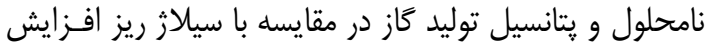
يافت.

\section{نتايج و بحث

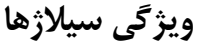

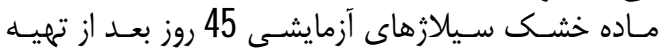

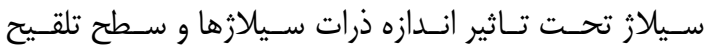

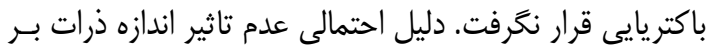

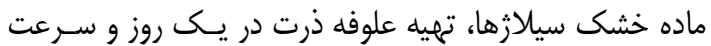

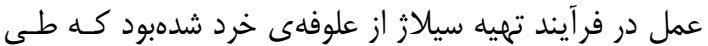

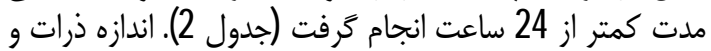

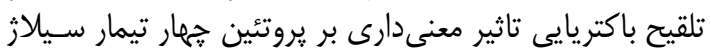

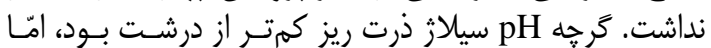

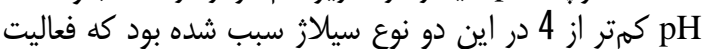

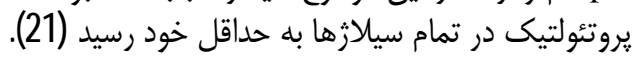

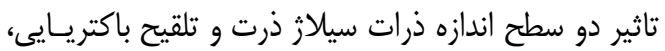

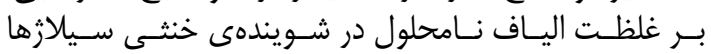

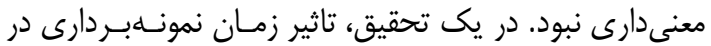

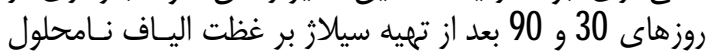

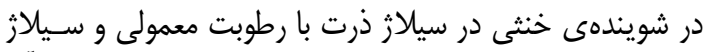

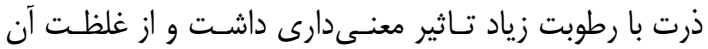

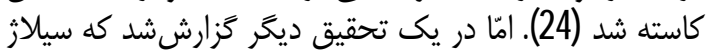

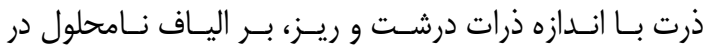

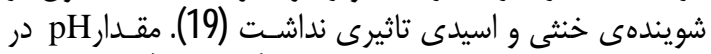

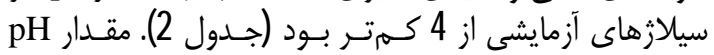

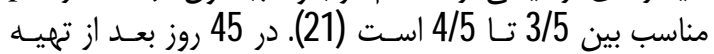

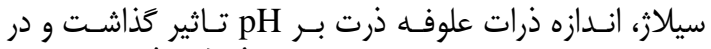

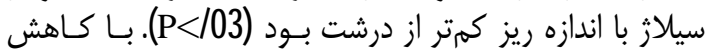

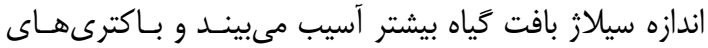

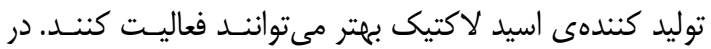

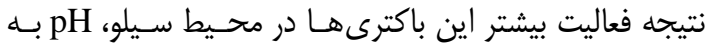

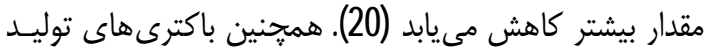

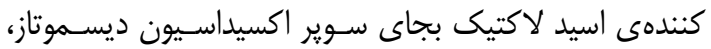

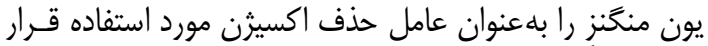

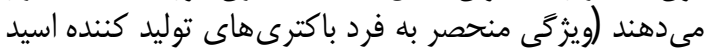

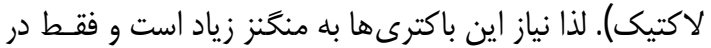
صورت آزاد شدن شيره كياهى، منكَنز به مقدار زياد در اختيـار

جدول - - تاثير دو سطح اندازه ذرات سيلاز ذرت و تلقيح باكتريايى بر تركيب شيميايى، پايدارى هوازى و توليد كاز در 45 روز بعد از تهيه سيلازهاى آزمايشى اندازه ذران

Table 2. Effect of two levels of corn silage particles size and bacterial inoculation on chemical composition, aerobic stability and gas production in 45 days after preparation of experimental silages

\begin{tabular}{|c|c|c|c|c|c|c|c|c|c|c|c|c|}
\hline \multicolumn{3}{|c|}{ سطح معنى دارى } & \multirow{2}{*}{ ميانكيار } & \multicolumn{2}{|c|}{ سطح تلقيح } & \multicolumn{2}{|c|}{ اندازه ذرات } & \multicolumn{2}{|c|}{ ريز } & \multicolumn{2}{|c|}{ درشت } & \multirow{2}{*}{ سطح تلقيح } \\
\hline متقابل & تلقيح & ذرات & & - & + & ريز & درشت & - & + & - & + & \\
\hline $\mathrm{C} / \mathrm{gL}_{2}$ & (/6) & प/ळ & $2 / 9$ & 2/1 & $2 / 6$ & $2 / \varepsilon$ & $2 / 1$ & $21 / \varepsilon$ & $2 / 4$ & 215 & 2/हE & ماده خشك (درصد) \\
\hline $\mathrm{C} / 9 \mathrm{~g}$ & C/9E & $C / 6$ & C/34 & $\varepsilon / 6$ & $\varepsilon / 6$ & $\varepsilon / 4=$ & $\varepsilon / 84$ & $\varepsilon / 41$ & $\varepsilon / 4 k$ & $\varepsilon / \mathscr{C}$ & $\varepsilon / \not \subset$ & يروتئين خام (درصد) \\
\hline$C / 5 E$ & $\mathrm{C} / 8 /$ & C/11 & C/01 & $4 / 6$ & $45 / 7$ & $30 / 1$ & $51 / 2$ & $4 C / 7$ & $4 E / 6$ & $4 E / 6$ & $5=/ \varepsilon$ & الياف نامحلول خنثي (درصد) \\
\hline$C / 45$ & $C / 2 E$ & $C / O E$ & $\mathrm{C} / \mathrm{IC}$ & छ/81 & $\Xi / \&$ & $\Xi / T^{\mathrm{D}}$ & $\Xi / 92^{a}$ & $\Xi / 7 \pi$ & $\Xi / 76$ & $\Xi / 84$ & $4 / \propto$ & $\mathrm{pH}$ \\
\hline $\mathrm{C} / \mathrm{C}$ & $<\mathrm{C} / 0]$ & $C / 0]$ & $6 / ब$ & $45 / \mathbb{G}^{\mathrm{D}}$ & $56 / \mathrm{C}^{\mathrm{a}}$ & $47 / \mathbb{C}^{\mathrm{D}}$ & $54 / \mathbb{G}^{\mathrm{a}}$ & $41 / 1$ & $54 / 7$ & $5 C / \varepsilon$ & $5 \mathrm{E} / 1$ & يايدارى هوازي (ساعت) \\
\hline$C / 4=$ & C/8 & $<C / O E$ & $\Xi / 2$ & $46 / 1$ & $4 k / 5$ & $4=/ \epsilon^{\mathrm{a}}$ & $41 / \varepsilon^{D}$ & $41 / \varepsilon$ & $4 / 2$ & $5 C / 4$ & $4 E / E$ & توليدكًاز ازبخش نامحلول د(ميليليتر) \\
\hline $\mathrm{C} / 84$ & $C / \varpi$ & C/OE & $3 / 32$ & $4 E / \varepsilon$ & $50 / \varepsilon$ & $47 / 5^{5}$ & $5=/ 1^{\mathrm{a}}$ & $4 \pi / 2$ & $4 / / 7$ & $52 / 4$ & $5=/ \varepsilon$ & يتانسيل توليد كازء (ميلىليتر) \\
\hline
\end{tabular}




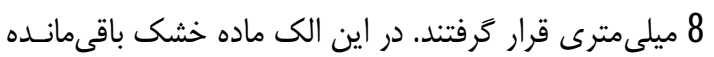

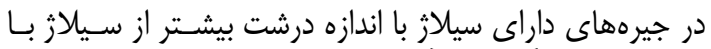

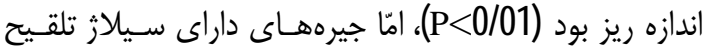

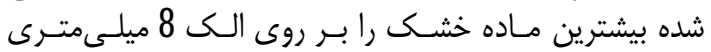

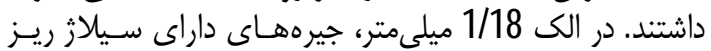

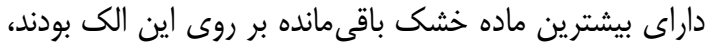

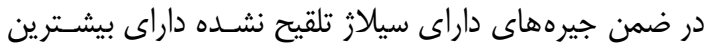

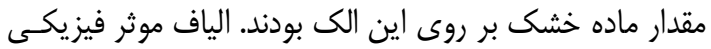

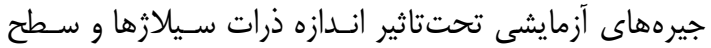

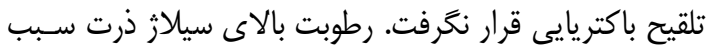

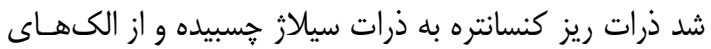

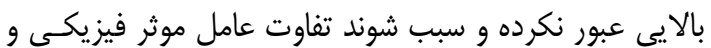

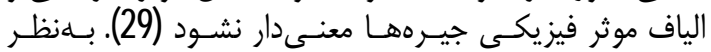

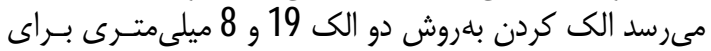

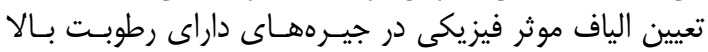

مناسبتر است (19).
ويزَّى هاى فيزيكى جيرهها

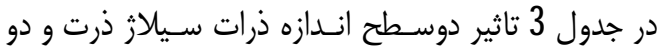

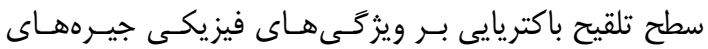

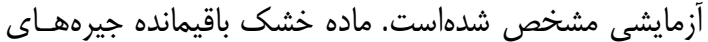

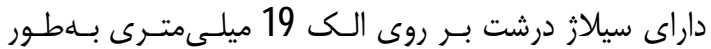

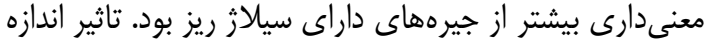

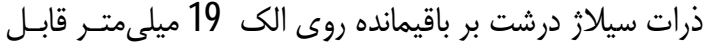

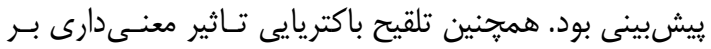

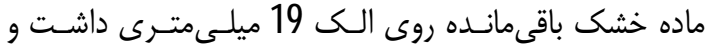

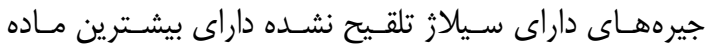

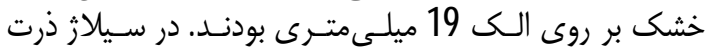

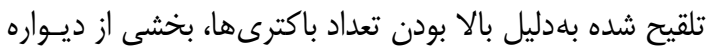

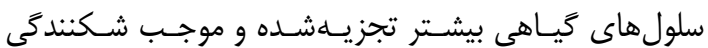

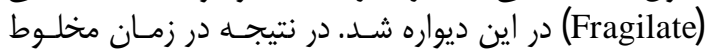

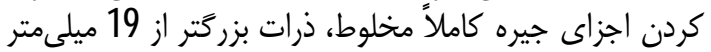

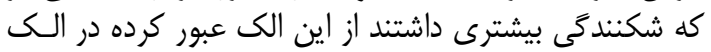

جدول3 - تاثير اندازه ذرات سيلاز ذرت و سطح تلقيح باكتريايى بر ويزگى هاى سيلازها Table 3. Effect of corn silage particles size and bacterial inoculotion on silages properties

\begin{tabular}{|c|c|c|c|c|c|c|c|c|c|c|c|c|}
\hline \multicolumn{3}{|c|}{ سطح معنى دارى } & خطاى & \multicolumn{4}{|c|}{ اثرات اصلى } & \multicolumn{2}{|c|}{ ريز } & \multicolumn{2}{|c|}{ درشت } & اندازه ذرات \\
\hline \multirow{2}{*}{ متقابل } & \multirow{2}{*}{$\begin{array}{l}\text { تلقيح } \\
\text { سطح }\end{array}$} & \multirow{2}{*}{ ذاندازه } & \multirow{2}{*}{ ميانكيير } & \multicolumn{2}{|c|}{ تلقيح باكتريايى } & \multicolumn{2}{|c|}{ اندازه ذرات } & \multirow{2}{*}{-} & \multirow{2}{*}{+} & \multirow[t]{2}{*}{-} & \multirow{2}{*}{+} & \multirow{2}{*}{ سطح تلقيح باكتريايى } \\
\hline & & & & 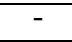 & $\dashv$ & ريز & درشت & & & & & \\
\hline & & & & & & & & & & 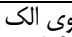 & 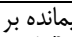 & ماده خشك \\
\hline$<C / 0]$ & $<C / 0]$ & $<\mathrm{C} / 0]$ & $1 / 5 C$ & $17 / 7^{\mathrm{a}}$ & $14 / \coprod^{0}$ & $11 / \epsilon^{0}$ & $27 / 2^{a}$ & $1 \mathrm{C} / \mathrm{I}^{\mathrm{a}}$ & $1 / 2 \mathrm{c}$ & $24 / \mathrm{F}^{\mathrm{a}}$ & $17 / 7^{\circ}$ & لـال ميلى مترى \\
\hline$C / O E$ & $<C / 0]$ & $<\mathrm{C} / 0]$ & $5 / 5=$ & $25 / \Sigma^{0}$ & $31 / \Sigma^{a}$ & $2 E /]^{0}$ & $31 / \mathrm{C}^{\mathrm{a}}$ & $E / 7$ & $2 E / E$ & $21 / 3$ & $36 / 5$ & ع ميلي مترى \\
\hline$C / \Sigma$ & $<C / 0]$ & $<\mathrm{C} / 0]$ & $2 / 3 x$ & $47 / \varepsilon^{\mathrm{a}}$ & $4 / \mathbb{I}^{\mathrm{D}}$ & $5 / \mathrm{G}^{\mathrm{a}}$ & $37 / 8^{0}$ & $56 / C$ & $4 \mathbb{E} / \mathbb{C}$ & $30 / 7$ & 35/C & ع1/1 ميليمترى \\
\hline $\mathrm{C} / \mathrm{Q}$ & C/11 & $C / \mathbb{Z}$ & $2 / 6$ & $\varepsilon / 9$ & IC/E & $10 / 4$ & $\mathrm{c} / 12$ & $\mathrm{c} / 41$ & $11 / \Xi$ & $\varepsilon / 36$ & $\mathrm{c} / \mathscr{C}$ & سينى \\
\hline C/8] & C/1] & $C / \mathbb{Z}$ & $2 / 6$ & $91 / C$ & $\mathbb{E} / 4$ & $\mathbb{E} / \mathrm{E}$ & $8 \mathcal{g} / \mathcal{E}$ & SC/E & $8 \varepsilon / 1$ & $91 / 6$ & $9 \mathrm{C} / 1$ & عاه \\
\hline C/81 & $C / O E$ & $C / 3$ & $C / 4 C$ & $35 / 6$ & 34/C & $35 / 4$ & $35 / 1$ & $35 / \mathrm{C}$ & $35 / C$ & $35 / 4$ & 3A/ع & الإل \\
\hline $\mathrm{C} / 24$ & C/๔ & $<\mathrm{C} / 0]$ & C/14 & E/4E & $6 / 35$ & $5 / 69^{\circ}$ & $7 / 3 C^{a}$ & $5 / 35$ & $5 / 52$ & $7 / 55$ & 7/17 & ميانكَين هندس \\
\hline - & - & - & - & $2 / \pi$ & $2 / 7 \varepsilon$ & $2 / 66$ & $2 / \&$ & $2 / 58$ & Z/TE & $2 / 92$ & $2 / 8 E$ & انحراف معيار ميانگين \\
\hline
\end{tabular}

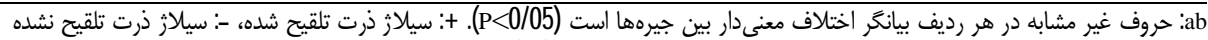

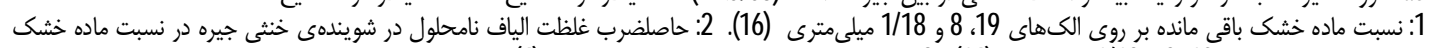

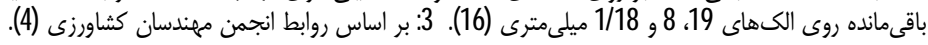

درصد كنسانتره (بر اساس ماده خشك) بــود. نتـايج تحقيقـات

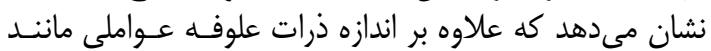

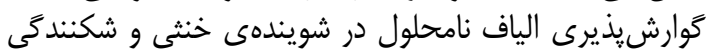

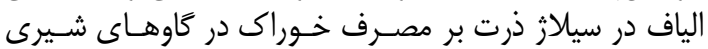
تاثير كذار مى باشد (12).

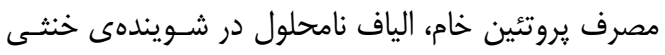

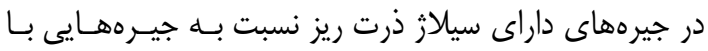

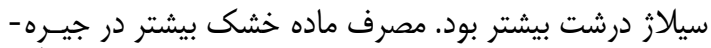

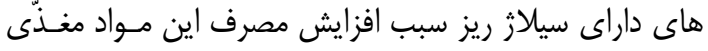

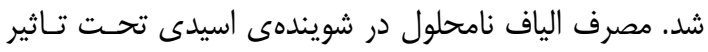

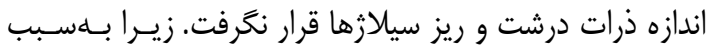

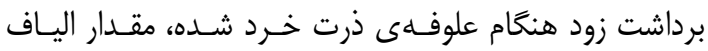

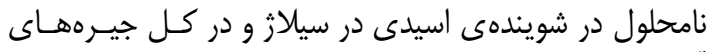

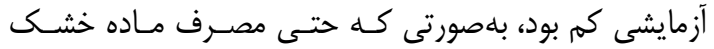

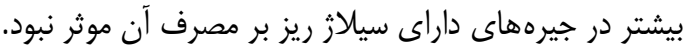

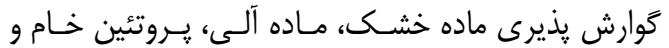

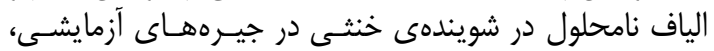

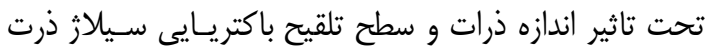

مصرف مواد مغذّى وَّوارش يذيرى

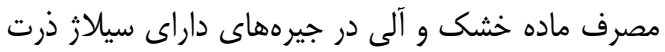

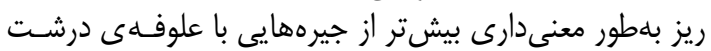

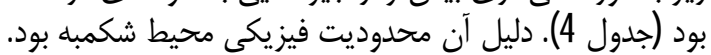

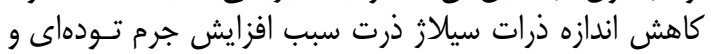

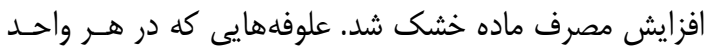

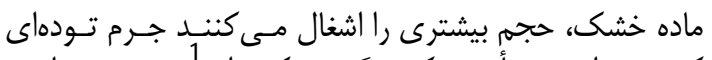

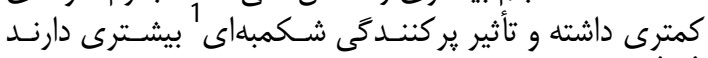

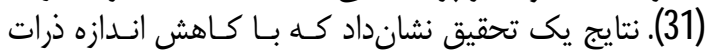

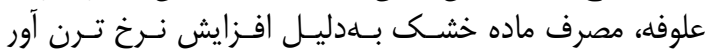

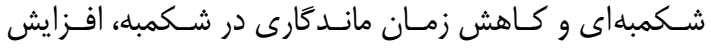

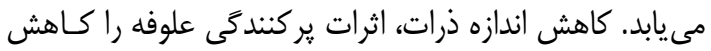

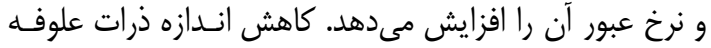

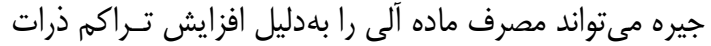

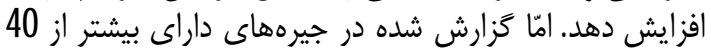

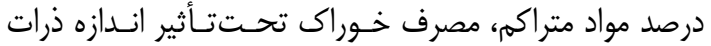

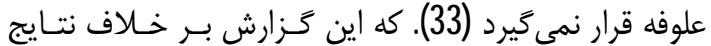

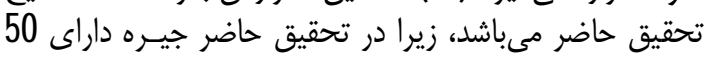


سيلازهاى ذرت كه تلقيح باكتريايى شدند تخمير كستردهترى

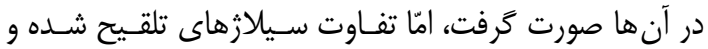

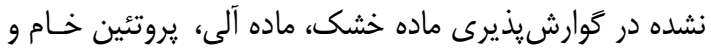

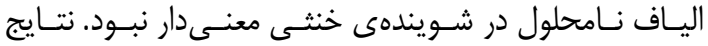

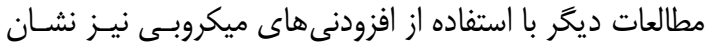

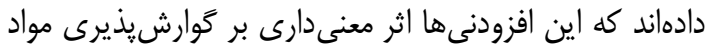
مغذى در دستخاه كوارش نداشتند (23).

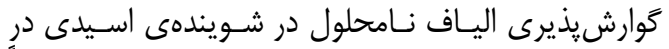

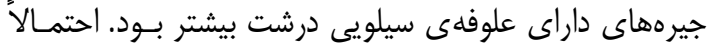

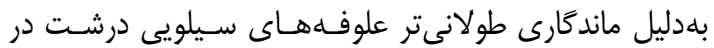

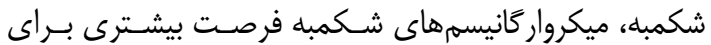

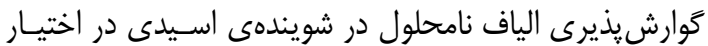

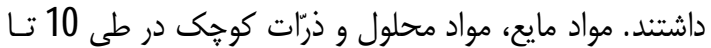

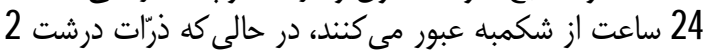
تا3 روز در شكمبه ماندًارى دارند (11).

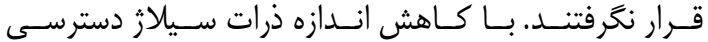

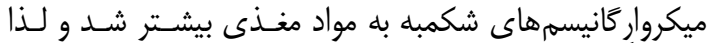

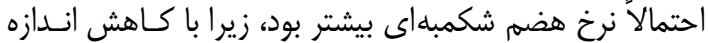

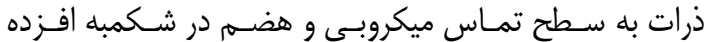

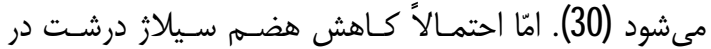

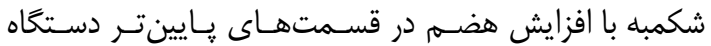

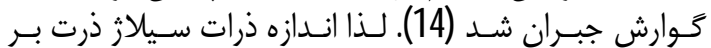

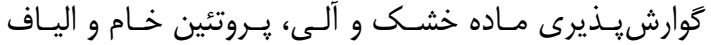

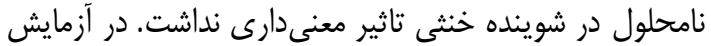

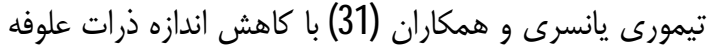

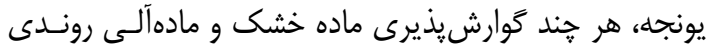

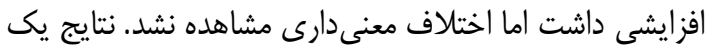

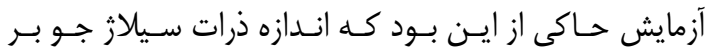

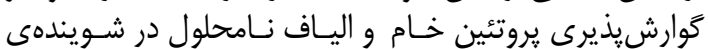

خنثى تاثيرى نداشت (29).

جدول4 - تاثير اندازه ذرات سيلاز ذرت و سطح تلقيح باكتر يايى بر مصرف و گوارشيذيرى مواد مغذى در جيرههاى آزمايشى Table 4. The effect of corn silage particles size and bacterial inoculation on nutrients intake and digestibility in experimental diets.

\begin{tabular}{|c|c|c|c|c|c|c|c|c|c|c|c|c|}
\hline \multicolumn{3}{|c|}{ سطح معنى دارى } & \multirow{2}{*}{ معيارى } & \multicolumn{2}{|c|}{ سطح تلقيح' } & \multicolumn{2}{|c|}{ اندازه ذرات؛ } & \multicolumn{2}{|c|}{ ريز } & \multicolumn{2}{|c|}{ درشت } & \multirow{2}{*}{ 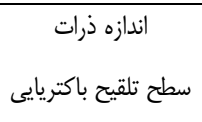 } \\
\hline متقابل & $\begin{array}{l}\text { تلقيح } \\
\text { سطيح }\end{array}$ & ذانداته & & - & + & ريز & ل درشت & - & + & - & + & \\
\hline$C D 1$ & $C / F^{2}$ & $\cos$ & C/75 & $7 / 7$ & $7 / 5=$ & $1 / \sigma^{a}$ & صصرف (ك) & $1 / \%$ & $1 / 64$ & & & 1 \\
\hline C/1ع & C/3 & C/OL & C/14 & $1 / 4$ & $\begin{array}{l}1 / 25 \\
1 / 3 x\end{array}$ & $\begin{array}{l}1 / 0^{-} \\
1 / 4 f^{a}\end{array}$ & $\begin{array}{l}1 / 4 C^{\circ} \\
1 / 34^{\circ}\end{array}$ & $\begin{array}{l}1 / 02 \\
1 / 4 k\end{array}$ & $\begin{array}{l}1 / 04 \\
1 / 4 C\end{array}$ & $\begin{array}{l}1 / 5 z \\
1 / 3 C\end{array}$ & $\begin{array}{l}1 / 42 \\
1 / 2\end{array}$ & آلر. \\
\hline C/17 & $C / 2$ & $\mathrm{C} / \mathrm{OL}_{2}$ & $\mathrm{C} / 01$ & $\mathrm{C} / 2$ & $\mathrm{C} / 2$ & $\mathrm{C} / 2^{\mathrm{a}}$ & $\mathrm{C} / 2 \mathrm{C}^{\mathrm{D}}$ & $\mathrm{C} / 2$ & C/22 & $\mathrm{C} / 2$ & $\mathrm{C} / \mathrm{IC}$ & 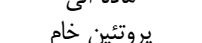 \\
\hline$C / 1=$ & $C / 27$ & $<\mathrm{C} / 01$ & $C / O E$ & $c / 6$ & $C / 5 C$ & $c / \sigma^{a}$ & $C / 5^{\mathrm{D}}$ & $c / \sigma=$ & $c / \sigma$ & $C / 51$ & $C / 5=$ & I \\
\hline C/8C & C/ळ & C/3 & $\mathrm{C} / \mathrm{EE}$ & $c / 2$ & $c / x$ & $\mathrm{C} / 3 \mathrm{C}$ & $C / 2$ & C/3C & C/3C & $c / x$ & $C / 2$ & الياف نامحلول اسيدى \\
\hline$C / 56$ & $C / 2 Z$ & C/2 & $\mathrm{C} / 01$ & $ஞ / 2$ & $7 / C$ & $\sigma / \varepsilon$ & $\varpi / 4$ & $๘ / 2$ & $6 / 14$ & $7 / 2$ & $ఠ / €$ & ماده خشك \\
\hline$C / 6=$ & $C / 5 C$ & $C / 1=$ & $\mathrm{C} / \mathrm{OI}$ & $71 / 4$ & $7 / / 4$ & $\sigma \Subset / \varepsilon$ & $T / C$ & $\pi / C$ & $\varpi / 6$ & $T / T$ & $7 \rrbracket / \Xi$ & ماده آلى \\
\hline$C / 54$ & C/9A & C/8: & $\mathrm{C} / \mathrm{CL}$ & $64 / \mathrm{C}$ & $\Subset / \subseteq$ & $64 / \mathbb{C}$ & $\varpi / 2$ & $64 / 1$ & $\varpi / \epsilon$ & $\varpi / \varepsilon$ & $6 A / E$ & يروتئين حام \\
\hline$C / T_{L}$ & $C / 4 E$ & $C / 26$ & $C / O E$ & $5 \mathrm{C} / 1$ & $5 / / 5$ & $56 / \mathbb{C}$ & $5 \mathscr{E} / 7$ & $5 E /]$ & $55 / 7$ & $60 / 2$ & $5 \mathrm{C} / 2$ & الياف \\
\hline $\mathrm{C} / 8 \mathrm{C}$ & $C / 9 E$ & $<\mathrm{C} / 01$ & $\mathrm{C} / \mathrm{CL}_{2}$ & $54 / 2$ & $54 / 2$ & $5 C / 5^{50}$ & $5 / / \mathbb{C}^{\mathrm{a}}$ & $5 C / 6$ & $5 C / 5$ & $5 / / \varepsilon$ & $5 / / \subseteq$ & الياف نامحلول اسيدى \\
\hline
\end{tabular}

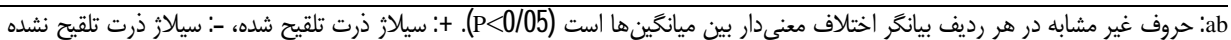

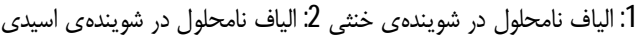

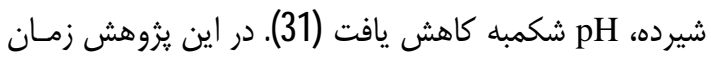

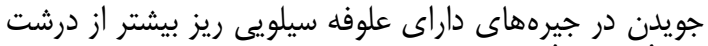

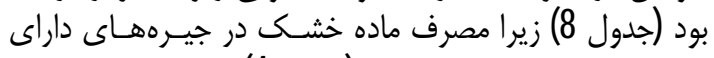

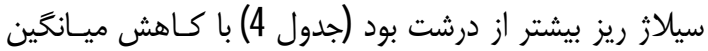

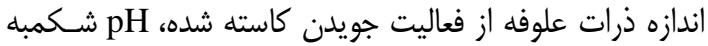

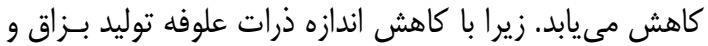

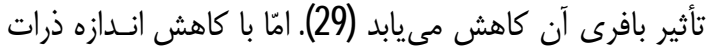

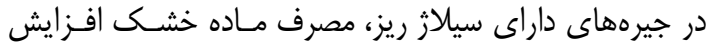

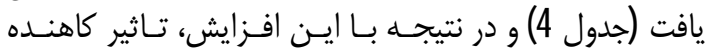

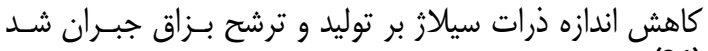

\section{مقدار pH شكمبهاى}

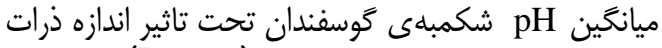

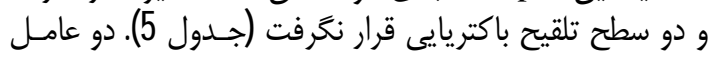

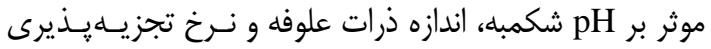

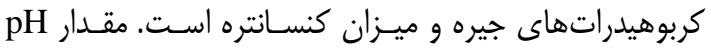

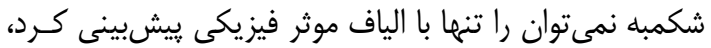

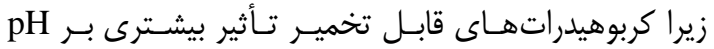

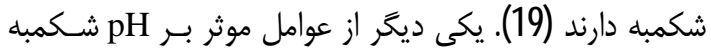
زمان فعاليت جويدن است.

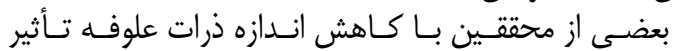

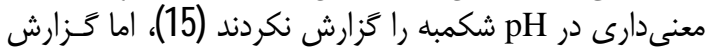

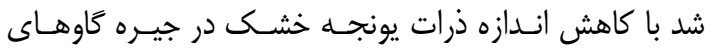


جدول 5 - تاثير اندازه ذرات سيلاز ذرت و سطح تلقيح باكتريايى بر pH مايع شكمبه در ساعات مختلف پٍ از تغذيه با جيرههاى آزمايشى Table 5. Effect of corn silage particles size and bacterial inoculation on pH of rumen fluid at different hours after feeding with experimental diets

\begin{tabular}{|c|c|c|c|c|c|c|c|c|c|c|c|c|}
\hline \multicolumn{3}{|c|}{ سطح معنى دارى } & \multirow{3}{*}{ معيانكين } & \multicolumn{4}{|c|}{ اثرات اصلى } & \multicolumn{2}{|c|}{ ريز } & \multicolumn{2}{|c|}{ درشت } & \multirow{3}{*}{ 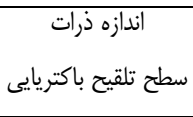 } \\
\hline اثر & سطح & اندازه & & \multicolumn{2}{|c|}{ تلقيح باكتريايى } & \multicolumn{2}{|c|}{ اندازه ذرات } & - & + & - & + & \\
\hline متقابل & تلقيح & ذرات & & 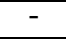 & t & ريز & درشت & & & & & \\
\hline $\mathrm{C} / \mathrm{T}_{2}$ & c/6 & C/11 & $\mathrm{C} / 22$ & $7 / 1$ & $7 / 27$ & 7/3] & $7 / 02$ & $7 / 3 C$ & 7/3 & كي بعد أز & ت نمونآب & صفر \\
\hline C/11 & C/Æ & $\mathrm{C} / 9 \mathrm{I}$ & $C / \propto$ & $6 / 5 c$ & $6 / 6$ & $6 / 5 C$ & $6 / 6 C$ & $6 / 52$ & $\epsilon / \sigma$ & $6 / 64$ & $6 / 5$ & دو \\
\hline $\mathrm{C} / 8$ & $C / 3 /$ & C/85 & C/12 & $6 / 71$ & $\epsilon / \mathbb{C}$ & $6 / 76$ & $6 / 74$ & G/TE & $\epsilon / \pi$ & $\epsilon / \mathscr{C}$ & $\epsilon / \pi$ & جهار \\
\hline C/4i & C/84 & $C / 9 C$ & $\mathrm{C} / \mathrm{C}$ & $\epsilon / 6$ & 6/6] & 6/6] & $\varepsilon / 6 C$ & $6 / 5 /$ & $6 / 64$ & $\epsilon / 6$ & $6 / 5 c$ & شش \\
\hline$C / 5 \varepsilon$ & C/31 & $C / 24$ & C/17 & $\epsilon / \mathbb{R}$ & $6 / 64$ & $\epsilon / \pi$ & $\epsilon / \sigma$ & $\epsilon / 82$ & $\varepsilon / 7 k$ & $6 / 74$ & $6 / 5=$ & هشت \\
\hline
\end{tabular}

داراى علوفهى ريز بيشتر بود زيرا با كاهش اندازه ذرات

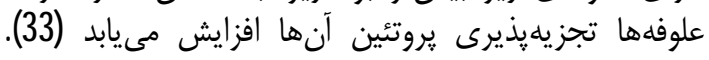

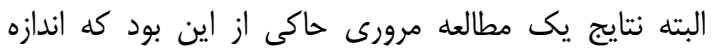

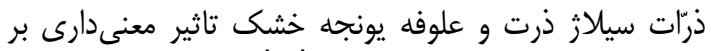

غلظت آمونياك شكمبهاى نداشتند (34).

\section{غلظت نيتروزن آمونياكى}

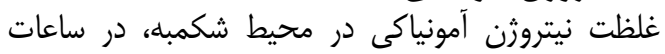

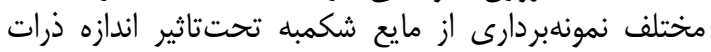

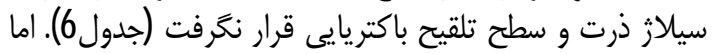

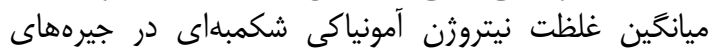

جدول6 - تاثير اندازه ذرات سيلاز ذرت و سطح تلقيح باكتريايى بر نيتروزن آمونياكى شكمبهاى در ساعات مختلف يس از مصرف جيرههاى

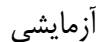

Table 6. Effect of corn silage particles size and bacterial inoculation on ruminal N-NH3 at different hours after consumption of dietary rations.

\begin{tabular}{|c|c|c|c|c|c|c|c|c|c|c|c|c|}
\hline \multicolumn{3}{|c|}{ سطح معنى دارى } & خطاى & \multicolumn{4}{|c|}{ اثرات اصلى } & \multicolumn{2}{|c|}{ ريز } & \multicolumn{2}{|c|}{ درشت } & \multirow{3}{*}{ 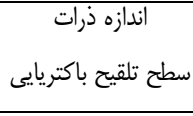 } \\
\hline \multirow{2}{*}{ متقابل } & \multirow{2}{*}{ تلقيح } & \multirow{2}{*}{ ذرات } & \multirow{2}{*}{ ميانكين } & \multicolumn{2}{|c|}{ تلقيح باكتريايى } & \multicolumn{2}{|c|}{ اندازه ذرات } & \multirow[t]{2}{*}{-} & \multirow{2}{*}{+} & \multirow[t]{2}{*}{ - } & \multirow{2}{*}{+} & \\
\hline & & & & - & -1 & ريز & درشت & & & & & \\
\hline$C / 64$ & $C / 4 C$ & C/17 & 4/14 & 12/7 & $1 / / 4$ & $1 \equiv / \bar{T}$ & $\mathrm{c} / 27$ & $14 / 2$ & $1 \Xi \equiv$ & $11 / 1$ & $7 / X^{-1}$ & صف \\
\hline C/1E & $C / T$ & $C / O S$ & $4 / 42$ & $\overline{E / C}$ & $2 / \varepsilon$ & $26 / 5$ & $2 \mathrm{C} / 2$ & $24 / 6$ & $2 \mathbb{2} /[$ & $2 E / 2$ & $17 / 2$ & دو \\
\hline $\mathrm{C} / 17$ & C/52 & $\mathrm{C} / 0 \mathrm{E}$ & $4 / Ø E$ & $1 \varepsilon / C$ & $1 E / 1$ & $2 \mathrm{C} / 1$ & $14 / C$ & $1 \varepsilon / \varepsilon$ & $21 / 2$ & $17 / 2$ & ]$C / \varepsilon$ & جهار \\
\hline C/2I & $C / \pi$ & C/L & $2 / 2$ & $\mathrm{I} / \mathrm{C}$ & $1 \equiv / 5$ & $14 / \overline{1}$ & 11/ع & $1 \Xi / 5$ & 15/G & $12 / 5$ & 11/] & شش \\
\hline C/12 & $C / \mathbb{R}$ & $C / 5 c$ & $4 / 07$ & $11 / 4$ & $1 C / 6$ & $11 / \subseteq$ & $1 \mathrm{C} / 2$ & $1 \mathrm{C} / 2$ & $14 / \mathrm{C}$ & $1 \equiv / 2$ & $7 / 24$ & هشت \\
\hline$C / 0=$ & $C / 4 C$ & $\mathrm{C} / 0]$ & 2/34 & $15 / \varepsilon$ & $14 / 7$ & $17 / 4^{\mathrm{a}}$ & $1 \Xi / 1^{\circ}$ & $16 / 2^{a}$ & $1 E / \epsilon^{\mathrm{a}}$ & $15 / 5^{\mathrm{ao}}$ & $1 C / \varepsilon^{0}$ & ميانخين كل \\
\hline
\end{tabular}

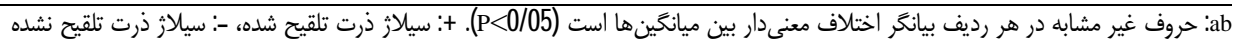

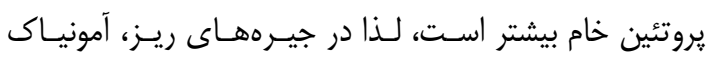

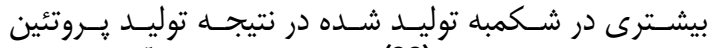

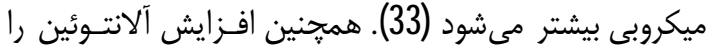

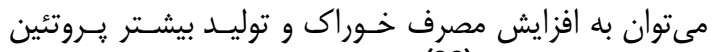

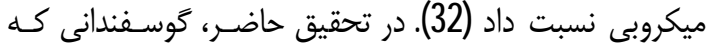

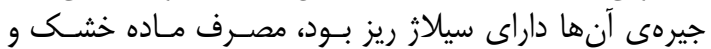

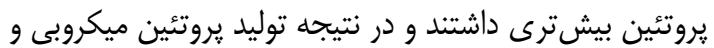

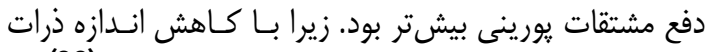

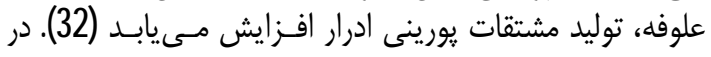

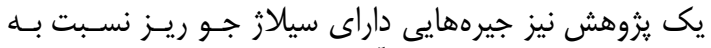

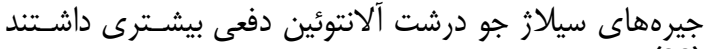

سنتز يروتئين ميكروبى الانتونين، إنيـ

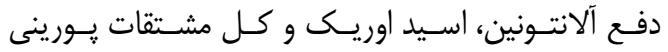

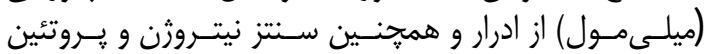

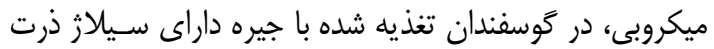

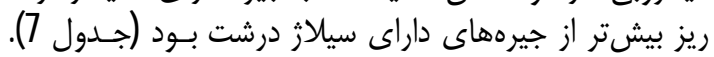

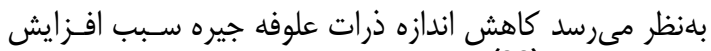

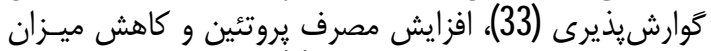

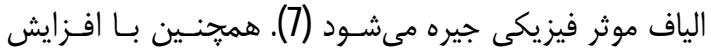

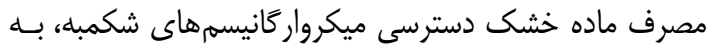

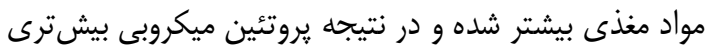

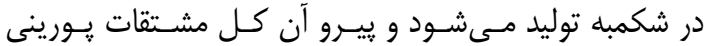

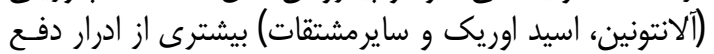

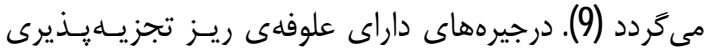


جدول7 - دفع مشتقات يور ينى و توليد بروتئين ميكروبى در گوسفندان تغذيه شده با جيرههاى آزمايشى(ميلىمول در روز) Table 7. excrete purine derivatives (mmol/ per day) and microbial protein sythesis (g) is in sheep fed with experimental diets

\begin{tabular}{|c|c|c|c|c|c|c|c|c|c|c|c|c|}
\hline \multicolumn{3}{|c|}{ سطح معنى دارى } & خطاى & \multicolumn{4}{|c|}{ اثرات اصلى } & \multicolumn{2}{|c|}{ ريز } & \multicolumn{2}{|c|}{ درشت } & \multirow{3}{*}{ 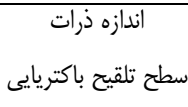 } \\
\hline اثر & سطح & أندازه & معيار & \multicolumn{2}{|c|}{ تلقيح باكتريايى } & \multicolumn{2}{|c|}{ اندازه ذرات } & \multirow{2}{*}{ - } & \multirow{2}{*}{+} & \multirow{2}{*}{ - } & \multirow{2}{*}{+} & \\
\hline متقابل & تلقيح & ذرات & ميانكين & - & -1 & ريز & درشت & & & & & \\
\hline C/34 & C/32 & $<\mathrm{C} / 01$ & $C / 9=$ & $\varepsilon / 2 \varepsilon$ & $5 / 56$ & $7 / 84^{a}$ & $4 / 0^{\circ}$ & T/\& & $7 / 8=$ & $4 / 6 C$ & $\exists 3$ & آلانتونين \\
\hline $\mathrm{C} / 0 \mathrm{~A}$ & $C / 9 C$ & $<\mathrm{C} / 01$ & $10 E$ & $C / 32$ & $C / 3=$ & $C / 3 x^{a}$ & $\mathrm{C} / 27^{\mathrm{D}}$ & $C / 3^{\mathrm{a}}$ & $C / 4]^{\mathrm{a}}$ & $\mathrm{C} / 3 \mathrm{C}^{\mathrm{D}}$ & $C / 2^{\circ}$ & اسيداوريك \\
\hline C/34 & C/32 & $<\mathrm{C} / 01$ & $1 / 0 E$ & $7 / 6 C$ & $6 / \&$ & $\mathrm{c} / 42$ & $5 / 1 C$ & $\mathrm{c} / 4$ & $\mathrm{c} / 4 \mathrm{C}$ & $5 / 8 c$ & $4 / 32$ & كل مشتقات يورينى \\
\hline$C / 2$ & $C / Z \mathcal{E}$ & $<\mathrm{C} / 01$ & $6 / 66$ & $3 C / \equiv$ & $3=/ 7$ & $4 \mathrm{C} / \mathrm{G}^{\mathrm{a}}$ & $2 \approx / C^{0}$ & $5 \mathrm{C} / \mathrm{C}$ & $4 \mathcal{E} / \varepsilon$ & $2 \varepsilon / 5$ & $17 / 5$ & يروتئين ميكروبى \\
\hline
\end{tabular}

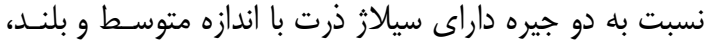

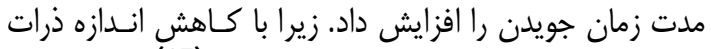

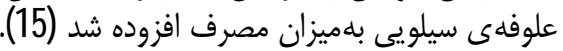

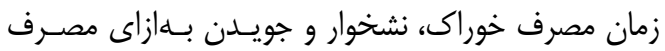

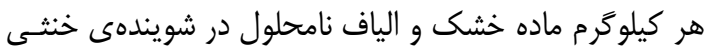

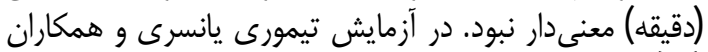

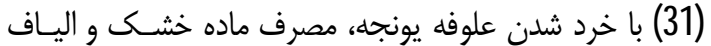

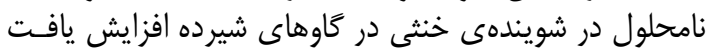

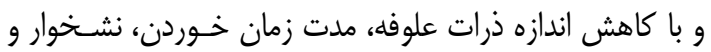

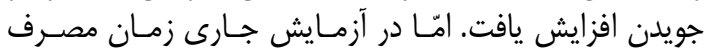

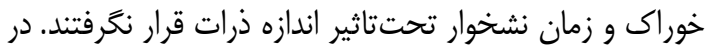

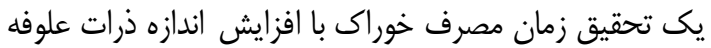

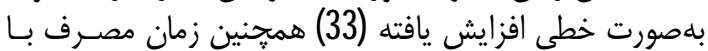

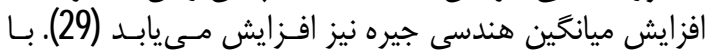

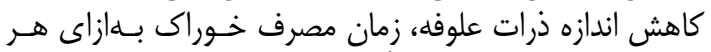

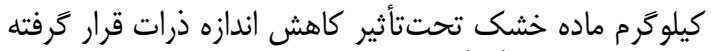

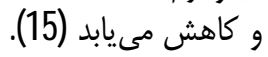

رفتار مصرف خوراك

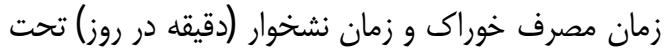

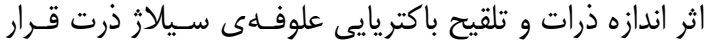

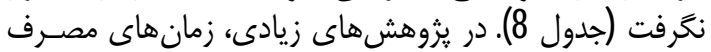

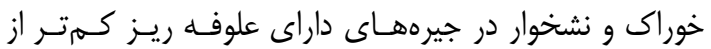

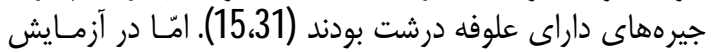

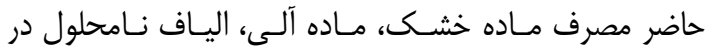

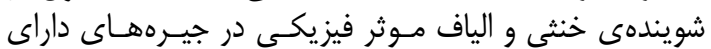

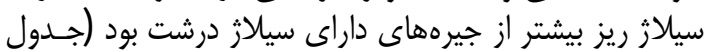

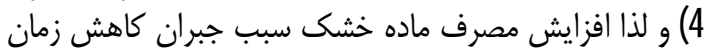

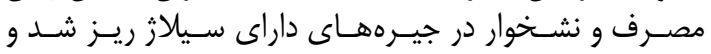

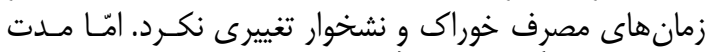

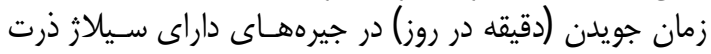

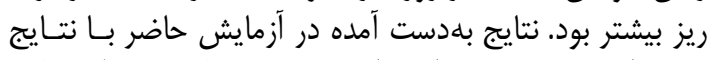

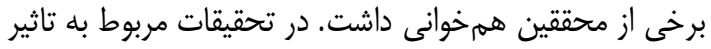

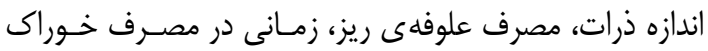

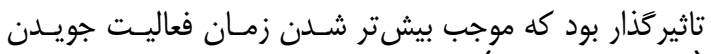

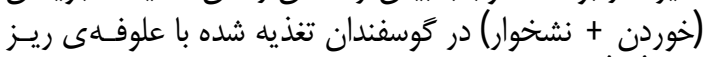

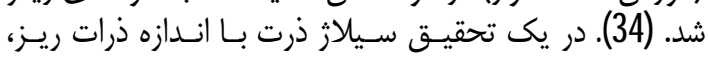

جدول 8 - تاثير دو سطح اندازه ذرات سيلاز ذرت و دو سطح تلقيح باكتريايى در سيلازهاى ذرت بر رفتار مصرف خوراك در گوسفند Table 8. The effect of two levels of corn silage particles size and two levels of bacterial inoculation in corn silage on

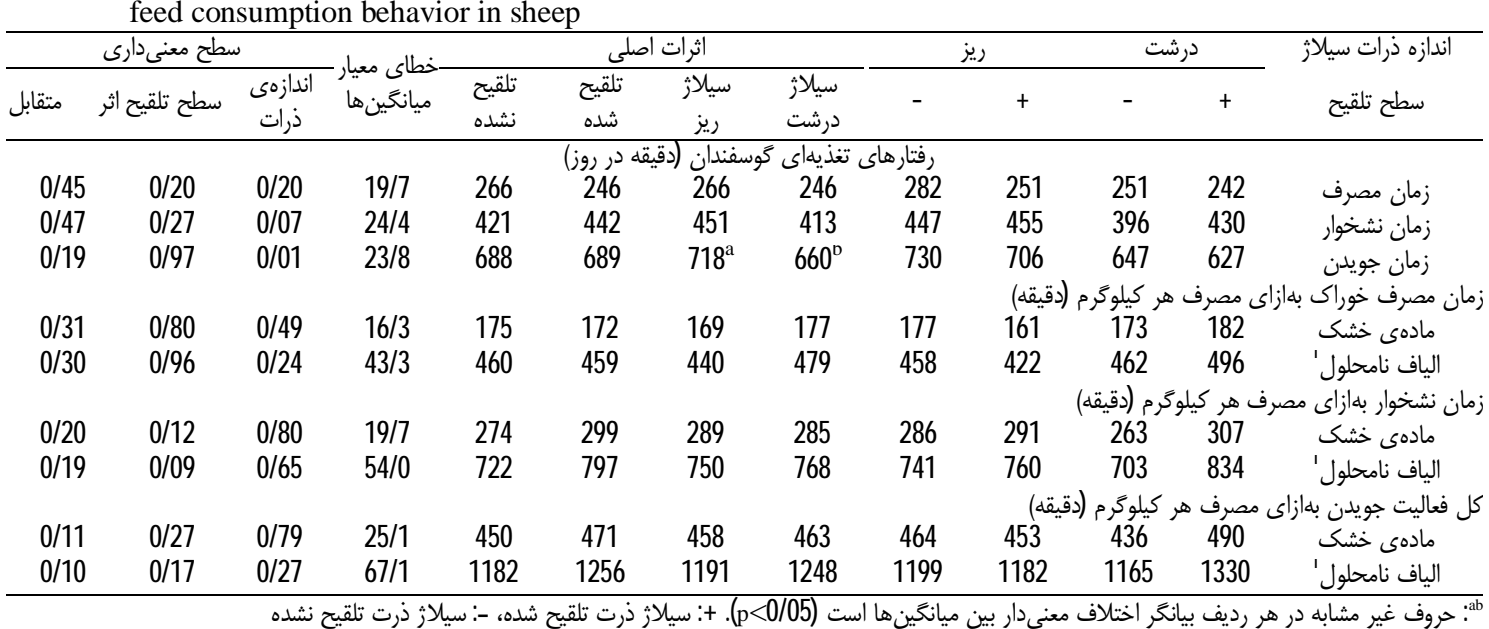

خشك، ماده آلى، يروتئين خام و الياف نامحلول در شـويندهى

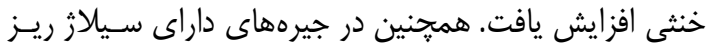

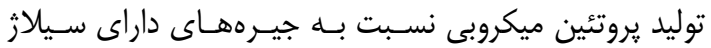
درشت بيشتر بود.

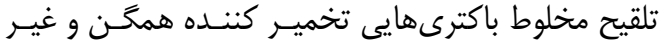

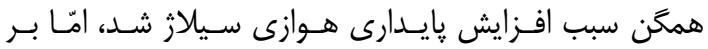

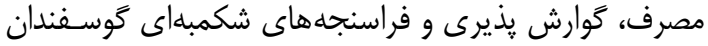
تاثير نداشت. با كاهش اندازه ذرات سيلاز ذرت فرئ مصـرف مـاده 
1. Acosta Aragon, Y., J. Jatkauskas and V. Vrotniakien. 2012. The effect of a silage inoculant on silage quality, aerobic stability and meat production on farm scale. ISRN Veterinary Science, 1-6.

2. Addah, W., J. Baah, P. Groenewegen, E.K. Okine and T.A. McAllister. 2011. Comparison of the fermentation characteristics, aerobic stability and nutritive value of barley and corn silages ensiled with or without a mixed bacterial inoculant. Canadian Journal of Animal Science, 91: 133-146.

3. Ahmadi, K., H. Gholizadeh, H.A. Ebadzadeh, R. Hossein Poor, H. Abdisheh, A. Kazemian and M. Rafiei. 2017. Agricultural statistics of the crop year 2015-2016. Ministry of Jihad-e-Agriculture, Deputy Director of Planning and Economics, ICT.

4. American Society of Agricultural Engineers (ASAE). 2002. Method of determining and expressing particle size of chopped forage (S424.1). $70^{\text {th }}$ ed St Joseph MI.

5. AOAC. 2005. Official Methods of Analysis of AOAC International, Maryland, USA.

6. Biomin Biostabil Mayas, 2018. Get more out of your corn silage with Biomin Biostabil Mayas: https://www.biomin.net/en/articles/get more out of your corn silage with biostabilr mays.

7. Broderick, G.A. 2003. Effects of varying dietary protein and energy levels on the production of lactating dairy cows. journal Dairy Science, 86: 1370-1376.

8. Broderick, G.A. and J.H. Kang. 1980. Automated simultaneous determination of ammonia and total amino acids in ruminal fluid and in vitro media. Journal of Dairy Science, 63: 64-75.

9. Chen, X.B. and G.B. Gomes. 1995. Estimation of microbial protein supply to sheep and cattle based on urinary excretion of purine derivatives- an overview of the technical details, Occasional Publication, Rowette Research Institute, Aberdeen, UK.

10. Contreras-Govea, f. and M. Muck. 2006. Microbial Inoculants for Silage. Focus on Forage, 8: 1-4.

11. Eyni, B. and M. Bashtani. 2016. Survey of nutritive value and degradability of sorghum silage from first and second cutting of f.orage. Research on Animal Production, 7: 136-142.

12. Faichney, G.J. 2005. Digesta flow. In, Dijkstra, J., J.M. Forbes, and J. France (Eds). Quantitative Aspect of Ruminant Digestion and Metabolism 2nd Ed. CABI Publishing, 49-86.

13. Grant, R. 2010. Forage fragility, fiber digestibility, and chewing response in dairy cattle. Tri state dairy conference, $27-40$.

14. Khorvash, M., D. Colombatto, K.A. Beauchemin, G.R. Ghorbani and A. Samei. 2006. Use of absorbants and inoculants to enhance the quality of corn silage. Canadian Journal of Animal Science, 86: 97-107.

15. Khosravi S., M. Asadi Fozi and A. Esmaili Koshkooyeh. 2018. Evaluation of genetic progress of growth traits in Kermani sheep breeding station. Research on Animal Production, 8:177-186.

16. Knapp, J.R., G.L. Laur, P.A. Vadas, W.P. Weiss and J.M. Tricarico. 2014. Invited review: Enteric methane in dairy cattle production: Quantifying the opportunities and impact of reducing emissions. Journal of Dairy Science, 97: 3231-3261.

17. Kononoff, P.J. and A.J. Heinrichs. 2003. The effect of CS particle size and cottonseed hulls on cows in early lactation. Journal of Dairy Science, 86: 2438-2451.

18. Kononoff, P.J., A.J. Heinrichs and D.R. Buckmaster. 2003. Modification of the Penn State Particle Separator and the effects of moisture content on its measurements. Journal. Dairy Science, 85: 18011803.

19. Kristensen, N.B., K.H. Sloth, O. Hojberg, N.H. Spliid, C. Jensen and R. Thogersen. 2010. Effects of microbial inoculants on corn silage fermentation, microbial contents, aerobic stability, and milk production under field conditions. Journal Dairy Science, 93: 3764-3774.

20. Lewis, W.D., J.A. Bertrand and T.C. Jenkins. 1999. Interaction of tallow and hay particle size on ruminal parameters. Journal Dairy Science, 82: 1532-1537.

21. Maulfair, D.D. and A.J. Heinrichs. 2013. Effects of varying forage particle size and fermentable carbohydrates on feed sorting, ruminal fermentation, and milk and component yields of dairy cows. Journal of Dairy Science, 96: 3085-3097.

22. McDonald, P., R.A. Edwards, J.F.D. Greenhalgh, C.A. Morgan, L.A. Sinclair and R.G. Wilkinson. 2011. Animal nutrition. $7^{\text {th }}$ edition. Prentice Hall, Harlow.

23. McDonald, P.A., R. Henderson and S.J.E. Heren. 1991. The biochemistry of silage. $2^{\text {nd }}$ ed. Chalcombe Pub. Abersyth. U.K.

24. Mirzaei, M., M. Khorvash, G.R. Ghorbani, M. Kazemi-Bonchenari, A. Riasi and A. Nabipour. 2015. Effects of supplementation level and particle size of alfalfa hay on growth characteristics and rumen development in dairy calves. Animal Physiology and Animal Nutrition, 99: 553-564.

25. Oliveira, A.S., Z.G. Weinberg, I.M. Ogunade, A.A.P. Cervantes, K.G. Arriola, Y.Jang, M.C.M. Gonalves, D. Vyas, A.T. Adesogan. 2016. Meta-analysis of effects of inoculation with homofermentative and facultative heterofermentative lactic acid bacteria on silage fermentation, aerobic stability, and the performance of dairy cows. Journal of Dairy Science, 100: 4587-4603.

26. Oney, C.R., J.L. Gramkow, A.K. Watson, G.E. Erickson and J.C. MacDonald. 2018. The Effect of Inoculants on Nutrient Losses of Corn Silage and High-moisture Corn Stored in Mini Silos. University of Nebraska - Lincoln, Animal Science Department. 


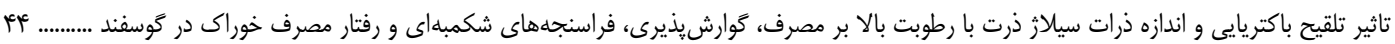

26. Oney, C.R., J.L. Gramkow, A.K. Watson, G.E. Erickson and J.C. MacDonald. 2018. The Effect of Inoculants on Nutrient Losses of Corn Silage and High-moisture Corn Stored in Mini Silos. University of Nebraska - Lincoln, Animal Science Department.

27. Pahlow G. and E. Zimmer. 1985. Effect of a lactobacillus inoculant on fermentation and aerobic stability of grass silage. Proceedings of the XV Int. Grassld. Congress, Kyoto, Japan, 8: 24-31.

28. Ranjit, N.K. and L. Kung. 2001. The effect of lactobacillus buchneri, lactobacillus plantarum as a chemical preservative on the fermentation and aerobic stability of corn silage. Journal Dairy Science, 83: 526-533.

29. Rymer, C. 2000. The measurement of forage in vivo digestibility. In: Forage Evaluation in Ruminant Nutrition, Edited by Givens, D.I., Owen, E., Omed H.M. and Axford. R.F.E, 113-134.

30. SAS. 2005. SAS User's Guide. SAS Institute Inc. Version 9. 1. Cary, NC, USA.

31. Shamsi Kushki, A. 2014. Effect of two levels of barley silage and two concentrate levels on physical properties of diet, feed intake, digestibility of nutrients, microbial protein synthesis and feed consumption behavior in m.ale Kerman sheep. Thesis of Animal Science, Shahid Bahonar University of Kerman, Iran (In Persian).

32. Sharifi, M., N.M. Torbati Nejad, A. Teimouri Yansari, S. Hasani and T. Ghoorchi. 2012. Effect of corn silage particle size and level of soybean oil on ruminal mat composition, distribution and consistency in Zel sheep. African Journal of Biotechnology, 11: 15580-15589.

33. Teimouri Yansari, A., R. Valizadeh, A. Naserian, D.A. Christensen, P. Yu and F. Eftekhari Shahroodi. 2004. Effects of alfalfa particle size and specific gravity on chewing activity, digestibility, and performance of Holstein dairy cows. Journal Dairy Science, 87: 3912-3924.

34. Theodorou, M.K., B.A. Williams, M.S. Dhanoa, A.B. McAllan and J. France. 1994. A simple gas production method using a pressure transducer to determine the fermentation kinetics of ruminant feeds. Animal Feed Science Technology, 48: 185-197.

35. Yang W.Z., K.A. Beauchemin. 2007. Altering Physically Effective Fiber Intake through Forage Proportion and Particle Activity and Ruminal pH of Dairy Cows Fed Diets Based on Barley Silage. Journal Dairy Science, 89: 217-228.

36. Zebeli Q., J.R. Aschenbach, M. Tafaj, J. Boguhn, B.N. Ametaj and W. Drochner. 2012. Invited review: Role of physically effective fiber and estimation of dietary fiber adequacy in high-producing dairy cattle. Journal of Dairy Science, 95: 1041-1056. 


\title{
Effect of Bacterial Inoculation and Levels of High-Moisture Maize Silage Particle Size on Consumption, Digestibility, Rumen Parameters and Feed Intake Behavior in Sheep
}

\section{Mohsen Dehghani ${ }^{1}$, Mohammad Mehdi Sharifi Hosseini ${ }^{2}$, Omid Dayani ${ }^{3}$ and} Ali Madahyan ${ }^{4}$

\footnotetext{
1 and 3- graduated and Professor of Shahid Bahonar University of Kerman, Faculty of Agriculture Department of Animal science

2- Assistant Professor Shahid Bahonar University of Kerman, Faculty of Agriculture Department of Animal science 4- Assistant Professor Payam Noor University of Kerman

Received: May 22, $2019 \quad$ Accepted: January 15, 2019
}

\begin{abstract}
This study was carried out to investigate the effect of bacterial inoculation on fine and coarse silage size with low dry matter, on the properties of silage and feed intake, digestibility and rumen parameters in Kermani sheep. Approximately 1200 kilograms of corn fodder were harvested in coarse and fine sizes (16 and $8 \mathrm{~mm}$, respectively). During the preparation of the silage, bacterial inoculation was added to $50 \%$ coarse and fine corn fodder. Four sheeps with two years old with an average weight of $36.1 \pm 1.6 \mathrm{~kg} \mathrm{BW}$ were used in the form of a Latin square design with a $2 \times 2$ factorial array with four 21-days period. The ratio of forage to concentrate in diets was 50:50 and includes: 1 ) The diet contains coarse inoculated corn silage, 2) The deit contains coarse unoculated corn silage, 3) The diet contains fine inoculated corn silage, and 4) The diet contains fine unoculated corn silage. Aerobic stability was the highest in inoculated rations and coarse silage diets $(\mathrm{P}<0.05)$. Consumption of DM, OM, NDF, ADF and peNDF, and digestibility of ADF were higher in fine silage diets $(\mathrm{P}<0.05)$. The synthesis of microbial protein was higher in a fine silage diets than coarse silage diets $(\mathrm{P}<0.05)$. The chewing activity was higher in fine silage diets than coarse silage diets $(\mathrm{P}<0.05)$. The results showed that inoculation of bacteria increased aerobic stability of low DM silage, but consumption of nutrients and production of microbial protein was higher in fine silage diets $(\mathrm{P}<0.05)$.
\end{abstract}

Keywords: Aerobic Stability, Corn Silage, Microbial Protein, Physical Effective NDF, Ruminal Parameters 